\title{
Resistência do Direito à Tecnologia: uma análise teubniana de comunicação e regulação
}

\author{
Resistance of the Law to Technology: A Teubnian Analysis of Communication \\ and Regulation
}

\begin{abstract}
Purpose - The article aims to confirm if there is resistance of the Law to Technology in order to admit the protagonism achieved by the second in the last years and to adjust the first to this new reality. Once confirmed the hypothesis, the purpose is to discuss how to overcome this resistance.

Methodology/approach/design - Review the works of Gunther Teubner, especially The Law as an Autopoietic System, in order to include Technology as a second-degree system, the same way that are Law, Economics and Politics.

Findings - Once is confirmed that the Technology was elevated to the category of a second-degree subsystem, the logic of the interaction between the other subsystems of the same classification will change and it will be demanded from Law the recognition of the new dynamics and its adjustment as to viabilize the communication as a mechanism of pre-regulation between itself and the Technology. Practical implications - Given the confirmation of the hypothesis and the fact that the Law is not yet able to internalize a version of reality that includes the Technology in an effective way, the text explores in what ways this scenario can be changed so that lawyers and law enforcers will acquire the grammar they need, being no longer technological-illiterates.
\end{abstract}

Originality/value - This article is original because it reviews Teubner's work on systems to add a new subsystem, Technology, while discusses the consequences of this change to the legal subsystem.

Keywords: law, technology, Teubner, communication, grammar.

\section{Resumo}

Propósito - O artigo objetiva confirmar se há resistência do direito em relação à tecnologia no sentido de admitir o protagonismo alcançado pela segunda nos últimos anos e se ajustar a esta nova realidade. Verificada a hipótese, o propósito será debater como superar essa resistência.

Metodologia/abordagem/design - Revisão das obras de Gunther Teubner, especialmente o direito como sistema autopoiético, para inclusão da tecnologia como sistema de segundo grau equiparado a direito, economia e política.

Resultados - Desde que a tecnologia foi alçada a categoria de subsistema de segundo grau, alterouse a lógica da interação entre os subsistemas de mesma classificação e passou a demandar-se do direito que se ajustasse e reconhecesse a nova dinâmica para viabilizar a comunicação como mecanismo de pré-regulação entre ele e a tecnologia.

Implicações práticas - Diante da confirmação da hipótese e da constatação de que o direito não está conseguindo internalizar eficazmente uma versão de realidade que inclua a tecnologia, o texto explora

*Advogada. Membro do IBRADEMP, ABDTIC e AASP. Graduada em Direito pela UFRN. Pós-Graduada em Direito Empresarial pela Fundação Getúlio Vargas e em Relações Internacionais pela UnB. Email: eduardachacon.adv@ gmail.com.

CHACON, E. M. Resistência do Direito à Tecnologia: um problema teubniano de comunicação e regulação. The Law, State and Telecommunications Review, Brasilia, v. 10, n. 2, p. 67-102, October 2018. [DOI: https://doi.org/10.26512/lstr.v10i2.21494] 
de que maneiras este cenário pode ser alterado para que os juristas e aplicadores do direito adquiram a gramática de que necessitam, deixando de ser tecnológico-iliteratos.

Originalidade/relevância - Este artigo é original porque revisita a obra de Teubner sobre sistemas para adicionar um novo subsistema, a tecnologia, e debater quais as consequências desta alteração em relação ao subsistema jurídico.

Palavras-chave: direito, tecnologia, Teubner, comunicação, gramática

\section{Introdução}

O trabalho parte da assunção de que a resistência do Direito à Tecnologia se origina em um dilema Teubniano de comunicação e regulação.

Tendo a tecnologia sido promovida a sistema social de segundo grau, ao lado do Direito, da Economia e da Política, o processo de acoplamento estrutural se conturbou porque encontrou os últimos ainda sem instrumental linguístico, que é a primeira fase da interação entre sistemas.

A solução para esta instabilidade depende de os juristas e aplicadores do direito se abrirem ao sistema Tecnologia e começarem a compatibilizar a realidade tecnológica com a realidade jurídica.

Ocorre que o jurista se encontra, atualmente, como um analfabeto tecnológico. Se o Direito não compreende a linguagem tecnológica, como será possível que apreenda uma versão da realidade social que é a tradução da realidade tecnológica?

Com vistas a solucionar este problema, o primeiro capítulo do artigo retrará a chamada questão do WhatsApp, episódios de suspensão dos serviços do aplicativo, para ilustrar na prática de que maneira o aplicador do direito, tecnológico-iliterato, reflete no mundo real a resistência do Direito quanto à Tecnologia.

Para assimilar o porquê desta resistência do Direito à Tecnologia, recorrerse-á à Teoria do Direito como Sistema Autopoiético de Gunther Teubner e se procurará estabelecer primeiramente que a Tecnologia é um sistema de segundo grau, hierarquicamente equiparado ao Direito, à Economia e à Política. Daí se buscará perceber como os sistemas se relacionam com os respectivos meios envolventes - próprios e mútuos e como evoluem a partir desta interação.

Deste ponto em diante, objetivar-se-á absorver o papel da regulação na teoria Teubniana para, enfim, iniciar a análise da relação entre o sistema Direito e o sistema Tecnologia como resultado de autorregulação, regulação mútua e evolução.

A partir do entendimento a respeito das razões que justificam a resistência do Direito à Tecnologia, sugerir-se-á um plano de conciliação com algumas demonstrações práticas de execução. 


\section{A Questão do WhatsApp: um grande mal-entendido}

A questão do WhatsApp (a ser desenvolvida neste capítulo) não deveria existir.

O que originou o equívoco foram ordens judiciais de suspensão do Over The Top Service (OTT) decorridas da falta de compreensão por magistrados a respeito de tecnicidades que regulam o funcionamento do aplicativo. ${ }^{1}$

Como se verá em maiores detalhes, a Tecnologia funciona de forma binária, trabalhando com possibilidades e impossibilidades técnicas insuperáveis.

Desse modo, quando uma decisão judicial desafia o determinismo tecnológico exigindo que programa execute um comando impossível, conclui-se que o autor da ordem não possui conhecimento técnico suficiente para arbitrar o conflito entre a aparente vontade da lei e o escopo da tecnologia.

A suposta violação do comando legal no caso do WhatsApp, que resultou em punição equivalente à suspensão do serviço, reflete um vício de comunicação entre Direito e Tecnologia e deste episódio decorreu uma enorme comoção social justificada, a princípio, pelo repúdio da sociedade à interferência do Judiciário - o que significa que o sistema legal não está conseguindo apreender de forma clara as mensagens do sistema social.

Aproveitando o ensejo a respeito da citada indignação social, as empresas de tecnologia capitanearam um movimento junto a organizações jurídicas e sociais para solicitar a interferência do Supremo Tribunal Federal (STF) na questão, alterando por judicial o Marco Civil da Internet de forma que jamais um OTT possa ser novamente suspenso ou bloqueado, não importa que circunstância fáticas se façam presentes no caso concreto.

Se a suspensão do WhatsApp nos casos que originaram as ações em trâmite no STF foi infeliz, a disposição legal que autoriza tais providências, contida no artigo 12 da Lei $n^{\circ} 12.965 / 14$, não é absurda, mas tem potencial de se provar cautela indispensável em outras oportunidades.

A ignorância do meio jurídico, generalizando o problema para os fins deste trabalho, está oportunizando que um equívoco judicial se torne subterfúgio para o ativismo judicial desacertado. Ao invés de bloquear disposições legislativas (por meio de demandas judiciais) para impedir que futuros enganos ocorram pela extinção da ferramenta jurídica, o correto seria aprimorar a gramática jurídica para que os operadores do Direito pudessem fazer uso correto dessas mesmas ferramentas.

\footnotetext{
${ }^{1}$ Para os fins deste trabalho, em consideração ao conceito de deniable encryption, considerar-se-á como verdadeira a alegação do WhatsApp de que já havia criptografia de ponta-a-ponta no seu sistema à época das ordens judiciais.
} 


\section{Criptografia}

Atualmente, o WhatsApp é construído de tal modo que, removida a criptografia, as mensagens não podem ser transmitidas pelo aplicativo. Não se admite, por configuração, transporte de informação em plaintext (texto plano ou decodificado).

Para que se removesse a criptografia da aplicação OTT, seria necessário alterar toda a sua estrutura para que passasse a aceitar este tipo de conteúdo.

Os criadores do WhatsApp alegam que tal alteração estrutural não poderia ser pontual (restrita a determinados usuários). Isto é: não se trata de garantir o sigilo das comunicações de uma única pessoa, mas de mais de um bilhão de usuários no mundo, cento e vinte milhões no Brasil (ESTADÃO, 2017).

Tem-se uma situação nova onde a regra no WhatsApp é, obrigatoriamente, que todos tenham criptografia ou ninguém tenha.

A criptografia end-to-end (E2E) recebe esta denominação porque somente o emissor e o receptor (as duas pontas), têm acesso ao conteúdo decifrado, o provedor apenas cria o túnel (termo técnico que designa o canal) por onde a comunicação é transmitida. $^{2}$

\section{Legalidade da criptografia}

O Marco Civil da Internet, Lei ${ }^{\circ}$ 12.965/2014 não tratou diretamente a questão da criptografia porque assumiu para si o papel preponderante de norma principiológica.

Nada obstante, seguiu ao Marco Civil o Decreto $\mathrm{n}^{\circ}$ 8.771, de 11 de maio de 2016, que veio regulamentá-lo e dispôs, expressamente, que os provedores de conexão e de aplicações deveriam adotar a encriptação ou medidas de proteção equivalentes para a garantia de inviolabilidade dos dados.

Art. 13. Os provedores de conexão e de aplicações devem, na guarda, armazenamento e tratamento de dados pessoais e comunicações privadas, observar as seguintes diretrizes sobre padrões de segurança: IV - o uso de soluções de gestão dos registros por meio de técnicas que

\footnotetext{
${ }^{2}$ Perfect forward secrecy (PFS) é um tipo mais seguro de criptografia do que o 2E2 "simples", porque consegue proteger o conteúdo armazenado em caso de comprometimento das chaves utilizadas - em caso de data breach, o conteúdo "para trás" é deletado. Além do PFS há os protocolos/sistemas/softwares de criptografia como o OffThe-Record (OTF), Pretty Good Privacy (PGP) [de Zimmermann] e OpenPGP (GNU Privacy Guard), todos assimétricos. A criptografia assimétrica é utilizada também pelo blockchain para as operações em criptomoedas (como Bitcoin), nos certificados digitais (como da $\mathrm{OAB}$ ) e em operações que necessitam segurança e autenticação. É também possível utilizar uma combinação das criptografias simétrica e assimétrica, como ocorre em muitas instituições bancárias.
} 
garantam a inviolabilidade dos dados, COMO ENCRIPTAÇÃO OU MEDIDAS DE PROTEÇÃO EQUIVALENTES (destacou-se).

O Decreto n. 8.771/2016 trouxe, no capítulo sobre proteção de dados, na Seção II ("Padrões de Segurança e Sigilo de Registros, Dados Pessoais e Comunicações Privadas"), a disposição de que os dados devem ser mantidos em formato interoperável e estruturado para facilitar o acesso decorrente de eventual decisão judicial ou determinação legal. Ou seja: no evento incerto e imprevisível de que sejam solicitados.

Portanto, se a criptografia é legal e os dados (existem, mas) estão armazenados no provedor de modo criptografado (logo, em condição inviável de compreensão), há duas alternativas: 1) equiparar esses dados criptografados a inexistentes (a menos que seja possível quebrar a criptografia) 2) ou aceitá-los no formato criptografado (apesar de serem inúteis - partindo do pressuposto de que a criptografia seja de qualidade, e como tal, inquebrável).

Em conclusão, não é possível censurar o WhatsApp ou qualquer outro aplicativo por lançar mão do recurso de encriptação - como recomendado pela lei.

\section{A Questão do WhatsApp}

Em março de 2016, o Juízo da Vara Criminal de Lagarto/SE ordenou ao WhatsApp que entregasse à polícia o conteúdo de conversas realizadas entre suspeitos sob investigação; a alternativa era a prisão de Diego Dzordan, vicePresidente do Facebook na América Latina, empresa proprietária do WhatsApp. Dzordan foi preso e liberado dois dias depois por ato do Tribunal de Justiça de Sergipe (GREENBERG, 2014; SREEHARSHA e ISAAC, 2016).

Antes da prisão, a multa, inicialmente arbitrada em R\$ 50 mil reais/dia, havia sido elevada ao patamar de um milhão de reais/dia. Em 02 de maio de 2016, o Juízo da Vara Criminal determinou que o WhatsApp fosse retirado do ar por setenta e duas horas com base no $\$ 2^{\circ}$ do art. 10 e nos incisos III e IV do art. 12 do Marco Civil da Internet. No dia seguinte, o Tribunal de Justiça de Sergipe revogou a decisão.

No final das contas, ao aplicar a criptografia 2E2, o WhatsApp cumpriu a lei, que calhou ter como resultado indesejável inviabilizar que se acessasse em plaintext o conteúdo de determinadas mensagens. A lei empoderou a plataforma OTT.

Quando a ordem judicial determinou que o WhatsApp entregasse o conteúdo das conversas, o que estava pedindo era um amontoado de caracteres sem sentido e sem utilidade, mas o que estava querendo era informação (plaintext) o que denota diferença entre o comando da ordem e a evidente intenção do magistrado. 
Ademais, outros mecanismos de investigação poderiam ser utilizados na falha da interceptação das conversas do WhatsApp ou, com o conhecimento técnico, a ordem judicial poderia ter sido elaborada de maneira viável.

O magistrado tinha a alternativa de ter requerido, por exemplo, metadados ${ }^{3}$; dados geolocalizacionais; filmagens, gravações, dados de operadoras financeiras, áudios, fotos, busca e apreensão de pendrives, Central Processing Units (CPUs), Universal Serial Buses (USBs), laptops, tablets, drones, equipamento fotográfico, smartphones de backups de fontes de atividades digitais e online do investigado; informações adquiridas a partir de empresas que utilizam GPS (global positioning system) nos aparelhos dos investigados (celulares, carros, smartwatches...); cópias de e-mails e acesso a redes sociais, etc.

\section{O Marco Civil da Internet sob julgamento}

Quase 90 anos atrás, o Justice Louis Brandeis, refletindo sobre o 'progresso da ciência' para além da escuta telefônica famosamente advertiu que 'os maiores riscos espreitam a liberdade no ataque traiçoeiro por homens zelosos, bemintencionados, mas sem compreensão' (APPLE, 2016 ${ }^{4}$ )

Repercutindo a questão do WhatsApp, que não se limitou a um (01) caso (Lagarto/Sergipe), estão pendentes de julgamento perante o STF uma Ação Declaratória de Inconstitucionalidade (ADI) $\mathrm{n}^{\mathrm{o}} 5527^{5}$ e uma Arguição de Descumprimento de Preceito Fundamental (ADPF) $n^{\circ} 403^{6}$, sob relatoria da Ministra Rosa Weber e do Ministro Edson Fachin, respectivamente.

O objeto da ADI n 5527 é a declaração da inconstitucionalidade dos incisos III e IV do art. 12 da Lei n. 12.965/14 (Marco Civil da Internet), e interpretação conforme do art. $10, \S 2^{\circ}$, para limitar o alcance da norma a casos de persecução criminal; alternativamente postula a declaração de nulidade parcial sem redução de texto do art. 12, III e IV, da Lei no . 12.965/14, para afastá-lo dos aplicativos de troca de mensagens virtual; ou, ainda, a interpretação conforme a Constituição a tais dispositivos, condicionando a aplicação das sanções de suspensão temporária e de

\footnotetext{
${ }^{3}$ São dados sobre os dados. Quem falou com quem, em que horários, quantas vezes, de que números. Essas informações não são encriptadas e são muito úteis em investigações.

${ }^{4}$ Livre tradução da conclusão da petição da APPLE no caso San Bernardino, sendo o original: "Almost 90 years ago, Justice Louis Brandeis, reflecting on the 'progress of science' beyond wiretapping, famously warned that " $t$ t] he greatest dangers to liberty lurk in insidious encroachment by men of zeal, well-meaning but without understanding." (Olmstead v. United States, 277 U.S. 438, 474, 479 - 1928). Conclusão da petição da APPLE no caso San Bernardino.

${ }^{5}$ STF, ADI 5527. Relatora Min. ROSA WEBER, audiência pública realizada nos dias 02 e 05 de junho de 2017. Pendente de julgamento.

${ }^{6}$ STF, ADPF 403. Relator Min. EDSON FACHIN, audiência pública realizada nos dias 02 e 05 de junho de 2017. Pendente de julgamento.
} 
proibição do exercício das atividades à frustração das sanções previstas no art. 12, I e II.

A ADPF $n^{\circ} 403$ propõe a vedação, em definitivo, de suspensão do WhatsApp por qualquer decisão judicial futura, sob pena de violação a preceito fundamental nos termos do artigo $5^{\circ}$, inciso IX da Constituição Federal, segundo o qual, independentemente de censura ou licença, se considera livre a expressão da atividade intelectual, artística, científica e de comunicação.

As ações estão sendo utilizadas - aproveitando a cobertura da questão na mídia e prestigiando os interesses de uma minoria privilegiada - como mecanismo transversal para alterar o Marco Civil da Internet e proibir o bloqueio ou suspensão de plataformas online no futuro, sob circunstâncias que hoje não podem ser previstas. Propõe-se destruir a ferramenta ao invés de ensinar ao operador como operá-la. Independentemente disso, o Judiciário não é competente para efetuar esta reforma legislativa e nem tem conhecimento técnico para fazê-lo.

\section{Problema de comunicação: juristas como técnico-iliteratos}

Sejam quais forem os resultados das duas ações em tramite perante o STF, é preciso que os operadores do direito assimilem como a tecnologia funciona para tomarem decisões que sejam coerentes com este conhecimento, ao invés de criar redes de segurança e cantoneiras de silicone para lidar com a falta de aptidão e conhecimento técnico (CHACON, 2016; CHACON, 2017).

Será inevitável que outros confrontos envolvendo determinismo tecnológico passem pelo Judiciário porque como disse Nate Cardozo, advogado da Electronic Frontier Foundation, "Não adianta usar a tecnologia para combater $o$ direito. $O$ direito combate o direito; a tecnologia combate a tecnologia" (CHACON, 2017).

O Direito precisa se atualizar, inserindo em sua gramática um vocabulário de tecnologia para que casos como o do WhatsApp sejam resolvidos com eficácia.

A partir da obra de Gunther Teubner, se buscará captar de que modo o Direito poderia construir esta gramática tecnológico-jurídica, em atenção à necessidade de alfabetização tecnológica dos juristas e aplicadores da lei, mas considerando a dificuldade de internalização de elementos do seu meio envolvente.

\section{Necessidade de conciliação entre Direito e Tecnologia}

Todo o segundo capítulo deste trabalho serve ao propósito de ilustrar a dificuldade do meio jurídico em dimensionar um problema tecnológico, compreendê-lo e solucioná-lo. 
Defende-se aqui que a razão para a questão do WhatsApp e todos os seus desdobramentos são resultado de uma gramática jurídica deficiente em relação à linguagem da tecnologia.

Soubesse o MM. Magistrado que deu origem ao caso do WhatsApp as noções médias de criptografia ou como busca-las, o aplicativo jamais teria sido suspenso. Não estivesse a sociedade civil tão assombrada ante a suposta possibilidade de bloqueios e suspensões aleatórios, não haveria espaço para a propositura de ações constitucionais inócuas como a ADI 5527 e a ADPF 403.

As próprias empresas de tecnologia se beneficiam da ignorância tecnológica no ambiente jurídico para fomentar debates que, em outro cenário, seriam despiciendos.

É preciso, certamente, discutir muitos aspectos legais, normativos e regulatórios, referentes à tecnologia, mas tais discussões não conseguem ultrapassar a fase inicial na qual os interlocutores desviam-se das problemáticas reais para perderem-se em argumentos retóricos e conceituais plantados nas mesas redondas com o objetivo de causar alterações, protelar soluções efetivas e desviar de temas incômodos aos players que comandam os lobbies.

Os aplicadores do direito, portanto, devem ajustar a gramática jurídica aos tempos atuais e, a fim de se tomar tal providência, é preciso questionar o sistema jurídico por inteiro, bem como os demais sistemas com os quais interage.

\section{Comunicação como a chave para a Teoria dos Sistemas de Teubner}

De acordo com Gunther Teubner, o Direito é um subsistema (sistema social de segundo grau) de comunicação que se tornou independente do sistema social de primeiro grau (sociedade), após o que passou a viver em clausura comunicativa (comunicando a respeito de si mesmo) - de modo que não há direito fora do direito -, o que exclui noções como direito natural ou direito divino.

O Direito constitui um sistema autopoiético de segundo grau, automizando-se em face da sociedade, enquanto sistema autopoiético de primeiro grau, graças à constituição auto-referencial dos seus próprios componentes sistêmicos e à articulação destes num hiperciclo (TEUBNER, 1993:53)

Sendo autorreferencial e autorreprodutivo, o Sistema Direito possui eventos comunicativos privativos que se multiplicam à luz de um código binário (legal/ilegal), em um processo circular, definindo as fronteiras do mundo jurídico e seu meio envolvente particular: a realidade jurídica.

A teoria dos sistemas autopoiéticos está assente no pressuposto de que a unidade e identidade de um sistema deriva da característica fundamental da autoreferencialidade de suas operações e processos. Isso significa que só por referência a si próprios podem os sistemas continuar a organizar-se e reproduzir-se como tais, como sistemas distintos de seu respectivo meio envolvente (TEUBNER, 1993:31) 
O Direito é para Teubner um sistema autopoiético que coexiste num universo de sistemas autopoiéticos com comportamentos semelhantes ao seu, o que dificulta o exercício da influência de uns sobre outros, inclusive quanto à regulação.

Teubner admite, em resposta a esta provocação, que a autonomia dos sistemas não exclui uma relação de interdependência mútua.

As normas extrajurídicas, todavia, se tornam jurídicas apenas se selecionadas e validadas pelo código do Sistema Direito e as normas jurídicas também deverão ser absorvidas de modo similar, levando em consideração códigos extrajurídicos.

A viabilidade da regulação depende de formas mais indiretas e reflexivas (de influências modeladoras filtradas) que levem em conta a autorregulação social. É preciso conciliar as duas afirmações anteriores: o fato de que a realidade jurídica é o meio envolvente do Direito, construída internamente com um circuito de comunicações jurídicas; mas também de que o Direito como sistema está sujeito a realidades extrajurídicas.

A resposta para este aparente dilema reside na comunicação. Embora os sistemas sejam todos autopoiéticos e possuam, como tais, códigos particulares, nenhum está excluído da comunicação social geral. Afim de que suas comunicações sejam compreendidas, é preciso que todos os subsistemas observem as fronteiras do discurso comunicativo global e as respectivas construções de realidade para que o sentido se torne a matéria-prima dos atos individuais de comunicação - o que se chama interferência (TEUBNER, 1993: XXVII).

A base reprodutiva desses sistemas sociais (incluindo interação, organização, sociedade geral) é constituída pelo sentido antes que pela vida (TEUBNER, 1993:64).

Surge a distinção entre clausura normativa e abertura cognitiva porque o fechamento autopoiético do sistema não pode aliená-lo do mundo extrajurídico. Desta feita, apesar de eventos extrassistêmicos não poderem funcionar como fonte direta de informação, os processos evolutivos internos do Direito podem ser estimulados por aqueles em um procedimento que será, em última instância, determinado pela autopoiese específica do sistema (order from noise).

\section{Sistema Tecnologia}

A Tecnologia evoluiu nos últimos anos galgando à posição de sistema de segundo grau, como o Direito, a Política e a Economia ${ }^{7}$. Isto resultou em uma

\footnotetext{
${ }^{7}$ Teubner descreve Sociedade, Economia, Direito e Política como os mais importantes subsistemas funcionais (TEUBNER, 1993:167). 
desestabilização nos ambientes envolventes dos sistemas autopoiéticos: realidades jurídica, política, econômica e, agora, realidade tecnológica.

0 sistema emergente, em vez de limitar-se meramente a reordenar os elementos existentes, cria verdadeiramente novas unidades a partir das unidades já existentes, que então se tornam elementos básicos do sistema (TEUBNER, 1993:47)

De facto, e desde logo, não apenas elementos do sistema, mas todos os seus componentes - elementos estruturas, processos, limites, identidade e unidade do sistema - devem ser auto-produzidos. Depois, não apenas o sistema em si deve ser auto-produzido, mas o próprio ciclo de auto-produção deve ser capaz de alimentar a si mesmo (TEUBNER, 1993:48)

Um sistema autopoiético de grau superior apenas pode ser desenvolvido a partir de um outro sistema autopoiético de aquele verdadeiramente 'produzir' os seus próprios elementos distintos dos elementos deste último: apenas podemos falar de um sistema autopoiético de grau superior se se provar que ele obedeceu a esta particular forma de emergência (TEUBNER, 1993:65).

O Sistema Tecnologia criou uma distorção no significado do discurso comunicativo (que repercutiu de maneira global) e das construções sociais de realidade (que é o ambiente comum a todos os sistemas). A dificuldade (até impossibilidade) de absorção de influências externas por causa da clausura autopoiética foi responsável por esta confusão e a única forma de restauração da harmonia entres os sistemas é a interferência como viabilizadora de evolução (NEVES, 2005:73).

interferência externa é a utilização da semântica de um sistema social para designar aspectos do outro - ter/não ter traduzido em poder/não poder (...) quando uma parcela do processo comunicativo (informação, participação e compreensão) é formulada em um sistema e completo o processo comunicativo em outro, ou então, quando, entre um processo comunicativo e outro subsequente nos mesmo sistema, ocorra um processo comunicativo necessário em outro sistema, que direciona a formação do sentido naquele primeiro (NEVESS, 2005:73).

O Direito, especialmente, se tornou defasado porque quando se fala em regulação, o sistema Jurídico se prepara somente para interferir (ativamente) nos demais subsistemas (observadas as limitações autopoiéticas), mas a recíproca não é verdadeira no sentido de uma heterorregulação de fora para dentro; daí porque o direito pressupõe a autorregulação (auto-molde) como regra ${ }^{8}$.

O que se observa é a necessidade de regulação inversa - do Direito pela Tecnologia - chamando-se regulação aqui à viabilização do acoplamento estrutural entre os dois para fins do primeiro ser estruturado pelo segundo.

${ }^{8}$ Todos os sistemas são autopoiéticos e hermeticamente fechados, não apenas o Direito. Teubner discorre sobre interferência para explicar como os sistemas interagem e se influenciam mutuamente, mas quando entra na seara da regulação, deixa a impressão de que o Direito é sempre regulador, não regulado.

CHACON, E. M. Resistência do Direito à Tecnologia: um problema teubniano de comunicação e regulação. The Law, State and Telecommunications Review, Brasilia, v. 10, n. 2, p. 67-102, October 2018. [DOI: https://doi.org/10.26512/lstr.v10i2.21494] 
A dúvida é de que forma o Direito poderia autorregular-se quanto à realidade da Tecnologia, se lhe falta a gramática para absorver, assimilar e reagir a tal demanda (o que se denominará neste trabalho de "pré-regulação", como um estágio anterior à regulação em si).

\section{Sistema Direito e relação com o meio envolvente}

Teubner afirma sobre o Direito que "o sistema politico exerce influência em todas as áreas da vida social por meio do direito” (TEUBNER, 1993:29). Porém a Tecnologia, ao contrário da política, exerce influência diretamente na vida social e não precisa do Direito para isso.

Se quer dizer com a sentença acima que a tecnologia não precisa se tornar uma comunicação jurídica autorrealizada para ser um fenômeno social. As comunicações tecnológicas se tornam realidade quando comunicadas, ainda que sem tradução para o formato de norma jurídica, de maneira que o mesmo fato pode originar dois fenômenos sociais muito distintos: um advindo diretamente da percepção social da realidade tecnológica e outro oriundo da percepçãotransformada-em-expressão-jurídica desta mesma realidade.

A diferença, para a Economia, por exemplo, seria que o fenômeno econômico dependeria da ferramenta de comunicação jurídica para se materializar como realidade social e a tecnologia não. A Tecnologia é um sistema mais moderno e mais independente em sentido estrito (apesar de todos os sistemas serem autônomos por causa dos hiperciclos).

O Direito, particularmente, costuma sofrer influência dos demais sistemas de modo indireto, sob o manto de uma repercussão (order from de noise):

a teoria autopoiética considera que a influência das condicionantes sociais, econômicas e políticas do direito não está excluída, mas é mesmo pressuposta por um sistema jurídico autoprodutivo. Não é a inexistência desta influência proveniente do meio envolvente que a teoria autopoiética veio inovadoramente sublinhar, mas apenas a forma particular como ela repercute no sistema (TEUBNER, 1993:45).

Os atos jurídicos são os elementos próprios que atuam como agentes de mudança e colocam o ciclo autopoiético em movimento; mas o ato jurídico não é o único componente do Direito, formado por processos, estruturas, limites e meio envolvente, todos eles autoconstitutivos e articulados entre si (hiperciclo). A autorreferencialidade aumenta conforme os componentes recebem maior feedback mútuo, variam sua plasticidade funcional ou estrutural e se multiplicam com a criação de novos componentes dentro das redes existentes (autodiferenciação).

A autonomia de todos os subsistemas é determinada pela definição autorreferencial de seus componentes (ao que se chama auto-observação) somada à operacionalização da auto-observação por meio de incorporação e articulação 
hipercíclica dos componentes autogerados que se produzem ciclicamente de modo recíproco - autopoiese (TEUBNER, 1993:68).

As auto-observações se dão espontaneamente em resposta aos fenômenos sociais que podem causar interações a serem discutidas externamente e cujo debate, eventualmente, se tornará objeto de outro debate; este pelos componentes dentro do sistema, em sua própria linguagem - como um filtro, no caso do direito, jurídico.

O conteúdo normativo dos elementos integrados é produzido dentro do próprio sistema jurídico por intermédio de normas constitutivas de referência, ficando assim essas 'incursões sociais' sempre sujeitas à reformulação jurídica (TEUBNER, 1993:75)

o sistema jurídico observa comunicativamente os seus próprios componentes, reduzindo-os a artefatos semânticos, que funcionam como 'abreviaturas' cristalizadas de factores sociais que passam a possuir existência própria.

Por outras palavras, trata-se de comunicações jurídicas que versam sobre e tematizam comunicações jurídicas - 'o direito do direito', como lhes chamaria Ewald -, gerando-se estruturas do sistema jurídico que regulam a selecção de outras e novas estruturas do mesmo sistema (TEUBNER, 1993:80 e 81)

Trata-se de um óbvio caso de auto-constituição de normas, já que é o próprio sistema que estabelece tais critérios, lançando mão de 'normas secundárias', ainda quando a 'substância semântica' dessas normas venha determinada exteriormente (TEUBNER, 1993:84)

A partir destas auto-observações se constatam variações que nada mais são do que o princípio evolutivo da autorreferência social. As variações poderão ser selecionadas conforme apresentem ou não uma vantagem evolutiva - o ponto não é a adaptação do sistema ao meio envolvente, mas a viabilização do sistema se libertar e se tornar mais autônomo.

A chave para a compreensão da autonomia do sistema jurídico reside nesta relação tripartida entre auto-observação, auto-constituição e auto-reprodução. Logo a comunicação jurídica sobre a distinção básica legal-ilegal comece a diferenciar-se da comunicação social geral, aquela torna-se inevitavelmente auto-referencial e é compelida a tematizar-se a si mesma no quadro de categorias intrinsecamente jurídicas (TEUBNER, 1993:70)

As normas jurídicas tornam-se numa espécie de abreviaturas ou cristalizações semânticas dos valores sociais subjacentes que, todavia, se vão libertando simultaneamente desses mesmos valores: em consequência a relação entre direito e sociedade torna-se cada vez mais tênue, o primeiro nem sempre refletindo adequadamente as necessidades e valores da segunda, e automizandose por vezes ao ponto de se tornar possível transplantar ordens jurídicas em blocos para contextos sociais completamente diversos (TEUBNER, 1993:83)

Sendo o sistema jurídico forçado a entender componentes internos de acordo com suas próprias categorias (gramática jurídica), estabelecerá normas reguladoras de suas próprias operações, estruturas, processos, limites, meio envolvente e identidade. A autonomia, portanto, é vista como a capacidade de 
autorregulação do Direito, que irá auto organizar-se ou alterar-se espontaneamente com o emprego da autorregulação (TEUBNER, 1993: 71 e 72).

A autonomia não exclui, nada obstante, a dependência do Direito em relação aos Sistemas Econômico, Político e, agora, Tecnológico. Por isso a distinção entre circularidade e independência causal, a primeira referente à autonomia jurídica e a segunda à relação com o meio envolvente (conceitos distintos embora relacionados).

Se o sistema Direito cria seus princípios, ações jurídicas, processos e institutos, para que esta organização reflita a Tecnologia, é preciso que a gramática jurídica incorpore um vocabulário tecnológico que habilite o sistema a receber comunicação de interesse e natureza tecnológicos.

Em face da caraterística circularidade de organização interna do sistema jurídico, os modelos de causalidade explicativos das influências externas se tornam mais complexos, devendo por isso substituir-se a simples lógica causaefeito por uma lógica de 'perturbação'.

Nesta acepção, a autonomia jurídica não exclui, mas antes pressupõe a possibilidade de interdependência entre sistema jurídico, sistema político e sistema econômico, com a ressalva de esta ser aqui perspectivada e entendida como um problema de influência externa sobre processos causais circulares internos. (TEUBNER, 1993:74).

Na verdade, Teubner explica que o direito não é produzido pelos juristas, mas é fruto de uma realidade emergente (comunicação jurídica autorrealizada), de maneira que as normas jurídicas são fenômenos sociais (aos quais a Tecnologia pode interessar) que se tornam realidade no momento em que são comunicadas.

A dificuldade é que a chamada realidade jurídica (como a tecnológica ou a econômica) não é uma parcela da realidade social, mas uma construção do mundo conforme apreendido pela comunicação jurídica.

É neste instante que entra em ação o acoplamento estrutural como mecanismo pelo qual um sistema coloca em funcionamento seus próprios elementos utilizando as estruturas de outro sistema sem confundir os limites entre ambos - o que se denomina relação intersistêmica.

\section{Evolução do Sistema Jurídico: demanda social e tecnológica}

A evolução do Direito pode ser estimulada, mas nunca causada pelo exterior. Deste modo, quando as estruturas sociais se alteram, geram estruturas normativas sociais que podem causar indiretamente variação nas normas jurídicas.

O efeito modelador das estruturas e normas sociais no Direito é de simples estímulo. Os conflitos sociais estimulam processos internos sistêmicos de formulação jurídica na medida em que são traduzidos para a linguagem jurídica 
depois de serem reconstruídos de modo autônomo dentro do sistema jurídico como conflitos jurídicos.

Por isso, Teubner entende que o direito não evolui por causa do conflito social, mas pelo eventual conflito jurídico que é a tradução daquele e que pode até mesmo ser irreconhecível para os litigantes (que participaram do conflito social/originário).

O nosso pensamento pode ser resumido de seguinte modo: no contexto de processos de co-evolução, a seleção das mudanças e inovações no direito não é apenas imputável à autopoiesis do próprio sistema jurídico, mas também, ainda que de modo bastante mais indirecto, à autopoiesis doutros sistemas sociais e da própria sociedade (TEUBNER, 1993:123)

Quando ocorrem estímulos de evolução simultaneamente enviados e recebidos por vários subsistemas, desde que superada a dificuldade de conciliação, podem acontecer pressões sistêmico-evolutivas recíprocas e coevolução.

Se a dificuldade de co-evolução ameaçar a sobrevivência dos sistemas, voluntariamente são introduzidos mecanismos de regulação que se destinam a mediar a interação e assistir na co-evolução.

Sistemas de negociação intersistêmicos são desenhados pela regulação com o fito de compatibilizar visões e expectativas.

Perceba-se que Teubner trata da dificuldade de compatibilizar pontos de vista e ambições entre os sistemas, mas o que se defende neste trabalho é que o desenvolvimento do Sistema Tecnologia agravou o quadro porque reinicializou a comunicação (globalmente) adicionando a gramática tecnológica ao processo absorvida pelos demais sistemas em tempos e graus diferentes, sendo o sistema Jurídico o que lhe opõe maior resistência.

Significa dizer que o Direito tem dificuldade de observar e traduzir em linguagem jurídica fenômenos tecnológicos, mantidos à margem da mundividência jurídicas - ao contrário dos fenômenos sociais, econômicos e políticos que são internalizados em um fluxo contínuo.

\section{Regulação como mecanismo de evolução}

Teubner questiona "como é que o direito vê e apreende a realidade jurídica da autonomia (social), de modo a ser capaz de a regular (qualquer que seja o sentido dessa regulação)?" (TEUBNER, 1989. P. 137).

A resposta a esta pergunta seria o primeiro passo para que se compreendesse como a regulação ocorrerá, porquanto para os sistemas regularem a si próprios e controlarem-se mutuamente, é preciso, antes, que tenham uma opinião interna (certa ou errada) acerca dos demais - não se pode regular o desconhecido, é preciso ao menos uma versão do desconhecido. 
É pertinente destacar, quanto à Tecnologia, que existe uma falha na apreensão pelo Direito da autonomia tecnológica (que a promoveu a sistema de segunda grau), o que é um enorme entrave à regulação desta.

Sendo a sociedade um sistema autopoiético de comunicações, seus atos de comunicação geram novos atos de comunicação, até que formados diversos circuitos de comunicação, um deles desenvolva tamanha autonomia ao ponto de se transformar em sistema de segundo grau.

Trata-se de unidades de comunicação autónomas que são, por seu turno, autoreprodutivas, gerando os seus próprios elementos, estruturas, processos e fronteiras, construindo o seu próprio meio envolvente e definindo sua própria identidade (TEUBNER, 1993:138)

Que a Tecnologia alcançou esse status é inegável. Discute-se, hoje, na Suprema Corte dos Estados Unidos se ter um celular é ato discricionário de natureza voluntária ou imposição da vida; e quais seriam as consequências de uma ou outra resposta em relação ao direito de privacidade dos dados de geolocalização (SELBST e TICONA, 2017).

Diante disso, o conceito de direito reflexivo se define como a situação em que "o sistema jurídico se identifica a si mesmo como um sistema autopoiético num mundo de sistemas autopoiéticos, e extrai dessa auto-identificação consequências operacionais" (TEUBNER, 1993: 138).

Daí a importância de autorregulação para corrigir a defasagem jurídica em relação à Tecnologia; caso contrário, será inviável atribuir-lhe qualquer função operacional eficaz nos âmbitos da vida social moderna que dependam da tecnologia (quase todos) e em relação às questões tecnológicas reguláveis.

Para tanto, o Direito precisa lidar com sua própria autopoiese e com a autopoiese dos outros sistemas sociais, dentre os quais o tecnológico, para que possa incluir em seu hiperciclo elementos informacionais advindos deste sistema em sua relação cognitiva com o respectivo meio envolvente.

\section{Como os eventos extrassistêmicos podem estimular processos evolutivos e regulatórios (order from noise)}

A realidade jurídica é o meio envolvente exclusivo do Direito, percebida como um modelo interno do mundo exterior a partir da qual se opera a abertura cognitiva do sistema jurídico, operativamente fechado. O mesmo se dá com os demais sistemas e suas respectivas realidades envolventes.

O desafio representado pela produção legislativa está nas autopoieses mútuas dos sistemas que tornam difícil o intercâmbio entre eles, sobretudo levada em consideração que a autonomia que os sistemas têm implica em autorregulação.

Teubner explica que a legislação ocorre no interior do sistema jurídico e culmina em um ato jurídico que, caso consista em informação juridicamente 
relevante, pode se reverter em princípio jurídico imperativo. Porém, para que se apliquem as pretensões jurídicas ao contexto social, sob a forma de decisões judicias concretas, é preciso sair do ambiente teórico do sistema Direito.

O sistema Político, a seu turno, instrumentaliza o direito como controle social e, neste ponto, a autonomia social torna-se um problema para a legislação (como heterorregulação) porque encontra as limitações de que os sistemas sociais - Direito e Político - são autopoieticamente fechados.

Os obstáculos à interação direta entre sistemas, todavia, seriam instransponíveis, pelo que restaria apenas recorrer a estratégias transversais, indiretas e marginais. A regulação, efetivamente, dependeria da ruptura dos circuitos comunicativos de todos os sistemas envolvidos no processo: regulador e regulados.

A ruptura da comunicação forçaria o fenômeno de order from noise: não alcançando o interior da clausura normativa social, o Direito se limita a fazer ruídos no mundo exterior; e a sociedade reage a estas ressonâncias externas.

$\mathrm{O}$ fechamento operacional atua a partir da abertura cognitiva dos demais sistemas, seja por formatos criados internamente ou irritações no ambiente que se transformam em irritações internas. Ao se apropriar do sistema de informações do ambiente, os sistemas iniciam um processo comunicativo interno por meio do acoplamento estrutural.

O acoplamento permite que os sistemas utilizem as estruturas de funcionamento uns dos outros para que o processo comunicativo de outro sistema deixe de ser mera perturbação e se torne um auxiliar de funcionamento das operações, malgrado o significado alcançado no processo só seja formado dentro do sistema no qual se realiza o processo comunicativo, de forma independente.

Teubner preocupa-se com a penetração do direito nos demais subsistemas; mas este trabalho questiona sobre a possibilidade de um caminho inverso, no qual outro sistema, como a Tecnologia, "romperia" a clausura do Direito.

\section{Regulação é exercício de observação, criatividade e percepção}

Sob uma ótica construtivista, as intervenções mútuas (no direito e na economia, para ilustrar), seriam apenas resultado de observação recíproca entre dois subsistemas autônomos. Um sistema imagina como é o outro - sem garantias e sem probabilidade [ou possibilidade?] de que esta imagem corresponda à realidade - e ambos agem concretamente a partir desse exercício de adivinhação ${ }^{9}$.

Em decorrência da reiteração destes exercícios, e para aperfeiçoá-los, é imperativo que os sistemas aprendam mais uns sobre os outros - olhem para fora.

\footnotetext{
${ }^{9} \mathrm{~A}$ elaboração e a promulgação de uma lei são exercícios cognitivo e normativo do Direito impossível de ser transladada a outro sistema (Teubner dá o exemplo de uma lei de controle de preços que não pode ser inserida no sistema da Economia) (TEUBNER, 1993:155-159). 
Mas por força da clausura comunicativa, se torna muito complicado absorver conceitos absolutamente desconhecidos como aqueles advindos da Tecnologia - o que leva à necessidade de se provocar uma evolução do Direito a partir das três ideias chaves de Teubner: 1) interação cega entre variação, seleção e retenção; 2) combinação entre desenvolvimento ontogenético e filogenético (acoplamento estrutural), e 3) co-evolução entre sociedade, direito e os outros sistemas sociais (TEUBNER, 1993: 104)

Segundo Teubner, "as observações recíprocas dos sistemas sociais não variam arbitrariamente, antes evoluem segundo padrões similares de variação (co-variação)" (TEUBNER, 1993: 161). Direito, Economia, Tecnologia podem apenas co-evoluir em isolamento mútuo, de maneira cega.

O sistema jurídico precisa melhorar seus conhecimentos sobre os componentes dos subsistemas regulados para moldar, em seu processo autopoiético, normas jurídicas que estejam em harmonia com as limitações e especificações científicas dos demais sistemas envolventes.

O que conduz de volta ao acoplamento estrutural, que torna possível um sistema emprestar a outro as estruturas necessárias para que realize suas operações - como a Economia e o Direito com uma lei de controle de preços.

Outra opção seria o sistema jurídico aumentar deliberadamente as hipóteses de variação dos cenários esperados para os sistemas "regulados" (interação cega entre variação, seleção e retenção).

Feitas estas ponderações, a melhor maneira para um sistema (especialmente o Direito) regular outro seria regulando a si mesmo com mais eficiência. Só assim se poderia conceber a lei como uma heterorregulação por meio da autorregulação (TEUBNER, 1993: 165)

\section{Regulação a partir da interação entre sistemas}

Inicialmente, Teubner leva a crer que não haveria saída dos circuitos fechados de auto-observação, e que seria impossível romper a circularidade.

Adiante, todavia, discorrendo sobre interferência intersistêmica, o autor muda a abordagem a respeito desta clausura intransponível, o que se inicia pela ressalva de que os sistemas autopoiéticos de segundo grau são passíveis de interferência quando homogêneos e resultantes de um processo de diferenciação a partir do mesmo sistema autopoiético mais abrangente. Direito, Economia, Política e Tecnologia se enquadram nesta hipótese.

A interferência possibilitaria o contato direto recíproco entre os sistemas para além da observação, mas não sem enfrentar as dificuldades de informação e motivação (TEUBNER, 1993:172 e 173).

No âmbito da interferência, faz-se uma distinção entre meio envolvente extrassocial e intrassocial. Por extrassocial são tidos os sistemas sociais que não 
se comunicam com, mas sobre o homem e a natureza, por intrassocial são tidos os sistemas que se comunicam por meio de uma ponte (a interferência) para articularem-se mutuamente a respeito de um evento comunicativo comum.

Os sistemas utilizam a matéria-prima do sentido, a partir da ferramenta comum da comunicação e da comunicação social geral. O significado disso seria que o mesmo elemento constitutivo que atua sobre a sociedade, age sobre os sistemas, sob a forma de atos de comunicação, tornando possível uma conexão virtual entre eles - de modo que todo ato de comunicação jurídica, política, econômica ou tecnológica será um ato de comunicação social geral.

A conclusão Teubniana é que entre os sistemas há tanto a interpenetração quanto a interferência e que no caso da primeira nenhuma relação seria possível ante a diferença entre os elementos dos sistemas, mas na segunda acontece um contato direto que se atribui inversamente à similitude entre estes elementos (TEUBNER, 1993:180).

É justamente o acoplamento estrutural mencionado em outras oportunidades.

Por meio do acoplamento estrutural, até estruturas linguísticas podem ser emprestadas entre sistemas para a realização de atividades comunicativas (na lógica particular do sistema que toma emprestado) e para a dotação de sentido e formação de repertório quando o código utilizado por um sistema é diverso e ininteligível para o outro (NEVES, 2005).

$\mathrm{O}$ acoplamento também pode significar perturbação e irritação em face de as estruturas emprestadas transmitirem a sensação de desorganização e bagunça para o sistema que toma emprestado. Essa desestabilização fortalece o sistema, auxiliando seu desenvolvimento (NEVES, 2005).

Interessa citar o problema dos conflitos do sistema (system conflicts), de que trata a obra Dilemmas of Law in the Welfare State, de Teubner, onde se questiona até que ponto o Direito desvia-se de sua base lógica ao interagir com outros sistemas, especialmente Política e Economia. Para evitar os desvios, o Direito deveria aumentar sua efetividade (mas para isso teria que deixar de ser orientação e virar política pública), reduzir a legalização (afastando-se dos demais sistemas) e investir em autorregulação (que seria para Teubner a melhor alternativa), (NEVES, 2005).

A dificuldade é identificar as mudanças estruturais que necessitam ser enfrentadas. O Direito precisaria se reformular, refletindo sobre o seu papel e a função da lei em relação aos demais sistemas.

Desta feita, volta-se ao que foi dito antes: que o direito precisa regular o direito com a consciência de que quanto mais afinado e afiado estiver, mais poderá contribuir socialmente e com os demais sistemas, via de consequência. 


\section{Tecnologia e Direito}

Adentrando o tema da Tecnologia, Teubner admite a existência do Cyberspace, onde seriam aplicados princípios de direito, dentre os quais os de direitos humanos e fundamentais que, a seu turno, concretizam direitos fundamentais específicos da internet - uma espécie de common law da Internet (lex digitalis).

The draw upon the fiction of a 'common core' of globally applicable principles of law, which include fundamental and human rights, and with their help concretize internet-specific fundamental rights within the reaches of a 'common law' of the Internet (TEUBNER e KARAVAS, 2005:12)

Este excerto é retirado do texto The horizontal effect of fundamental rights on "private parties" within Autonomous Internet Law, e desde o cabeçalho fica evidente a atribuição de autonomia à Internet (chamada ao longo deste trabalho Tecnologia para ampliar o escopo do Sistema, que vai além da internet).

Teubner e Karavas abordam o Código como "lei da internet", investindolhe a função de "digitalized embodiment of norms of conduct within the architecture of Cyberspace" (TEUBNER e KARAVAS, 2005: 14 e 15) e indagam de que formas o Código poderia colocar em risco a autonomia individual; perceber a autonomia das instituições econômicas; reconstruir os direitos fundamentais para se apropriem à tecnologia e, que procedimentos precisariam ser inseridos no Código para garantir os direitos fundamentais e a proteção da autonomia das esferas institucionais quanto a manifestações digitais de normas legais.

Os autores esclarecem as diferenças estruturais entre Código e Lei (Direito), como o fato de o primeiro ser autoaplicável, independendo do Governo e do Estado de Direito - este responsável pela criação da lei, sua aplicação e pela coerção legal.

A binariedade do Código é outra peculiaridade, porquanto o sistema processa eletronicamente a realidade ( $\operatorname{sim}$ ou não), sem que haja espaço para resolução dos conflitos de acordo com as expectativas sociais ou o caso concreto (casuística).

O binário da Tecnologia sempre será radical, matemático, terminativo. A tecnologia é um conjunto de 1's e 0' onde qualquer ação observada será de sim ou não, o que não varia caso a caso. Algo é possível ou impossível. Verdadeiro ou falso.

Teubner define o Direito como um sistema binário (legal e ilegal), mas em comparação à Tecnologia, a binariedade do Direito se torna fraca por ser permeada de exceções e técnicas hermenêuticas.

Nós sempre pensamos as questões jurídicas como corretas ou incorretas, algo ou é lícito ou é ilícito, ou é legal ou é ilegal. Agora, não. Então você joga nas mãos do juiz todas essas questões. Eu diria então que não só o juiz não tem um instrumental doutrinário, como ele tem uma carga de responsabilidade terrível. 
Se eu fosse juiz hoje, estaria angustiado (...) nós não temos ainda um desenvolvimento coerente de uma teoria jurídica para essa nova situação. Nós continuamos usando a teoria de um mundo físico anterior. É mais fácil para um juiz entender isso com os instrumentos antigos do que entender os instrumentos novos de tecnologia. Nós ainda trabalhamos com conceitos velhos. Os juízes operam conceitos velhos em um mundo novo (FERRAZ JÚNIOR, 2017)

Esta relação entre lei e tecnologia que pressupõe que a lei deve ser adaptada para levar em consideração novos formatos de práticas culturais, quer para proibi-las ou legalizá-las (...). Ambas as maneiras de adaptar a lei à tecnologia significam que a lei está tentando controlar a tecnologia, negativamente, proibindo certos comportamentos ou, de forma positiva, reconhecendo-os (ROSNAY, 2014)

The strict binary formulation, $0-1$, which is only relevant to a real world legal code in the systems theoretical sense of the distinction between 'legal' and 'nonlegal', extends, in a virtual world of legal programs, to inform legal decisionmaking in its entirety. This precludes any room for interpretational maneuver within the programs throughout the entire jurisdiction of the Code. Normative conduct expectations, which could always be interpreted, adapted, manipulated or bent, are becoming rigid cognitive expectations of factual circumstances (inclusion/exclusion). The esoteric forms of learning, which were always to be found in the permanent microvarations of law in the face of new facts or new social values, are excluded from the Code. Even legal arguments are excluded from the jurisdiction of the Code.

The Code has no room for those functions that were always allowed within traditional law: the making of exemptions, the application of equitable principles, the non-application of law, or, the simple recourse to non-legal forms of communication. Digitalization precludes the informal non-application of the Code. Given the demise of 'useful illegality', it is no wonder that the figure of the Hacker who endeavors to break the Code has become the modern embodiment of the Robin Hood myth (TEUBNER e KARAVAS, 2005:17)

Interessante que em outro texto (Rights of Non-humans: electronic agents and animals as new actors in Politics and Law), Teubner explica que o Direito está se abrindo para a Tecnologia (malgrado ressalve-se, aqui, que não com a eficiência que deveria) ao debater se agentes eletrônicos são atores de direito.

The result is that law is opening itself for the entry of new judicial actors animals and electronic agents. The differences in the outcomes, however, are striking (...) Animal rights and similar constructs create basically defensive institutions. Paradoxically they incorporate animals in human society in order to create defenses against destructive tendencies of human society against animals (...) For electronic agents, the exact opposite is true (...) Here their inclusion into society does not protect the new actors - just the opposite. It is society that needs to defend itself against the new actors. With the social inclusion of cyborgs and electronic agents, new problems of alienation appear at the horizon of the law (TEUBNER. 2006a.)

Teubner conclui o artigo perguntando, em tom de provocação, se as garantias constitucionais estarão em posição de contra-atacar o Código e a arquitetura eletrônica da internet; e se as transações técnicas, sociais e econômicas 
concretizadas por agentes eletrônicos serão devolvidas ao controle do homem (TEUBNER, 2006).

\section{Resistência do Direito à Tecnologia}

O Direito objetiva transformar realidades sociais em construções legais. A dificuldade é que nem sempre consegue ser efetivo ao abstrair a realidade social.

Defendeu-se, anteriormente, que a Tecnologia se alçou à condição de sistema de segundo grau ao lado da Economia, do Direito, da Política e da Sociedade. Viu-se, também, que a Tecnologia tem uma particularidade: o Código.

Passa-se que, na prática, a integração social é um jogo complexo porque pressupõe resolver conflitos entre as diferentes racionalidades de subsistemas sociais altamente especializados.

Malgrado os sistemas tenham seus próprios processos, realidades, componentes, elementos, etc., as construções legais são extraídas do Direito em resposta a um longo processo histórico evolutivo que se enraizou na interação intersistêmica e pelo acoplamento estrutural que viabilizou o intercâmbio entre estruturas linguísticas que foram mutuamente absorvidas (versões delas).

As leis econômicas, por exemplo, por mais que não correspondam às leis jurídicas, com elas se harmonizam, cada uma com seu âmbito de aplicação. Como mencionado anteriormente, Direito e Economia trabalham sob uma ótica construtivista de intervenção mútua quando é elaborada uma lei de fixação de preços, que não pode ser inserida no sistema Economia, mas é construída no sistema Direito a partir de um empréstimo de estruturas daquele que o articula quanto a aspectos de interesse econômico.

Com a Tecnologia é diferente porque o Direito resiste ao acoplamento estrutural que poderia lhe emprestar as estruturas linguísticas que permitiriam a criação e o desenvolvimento de uma gramática jurídico-tecnológica e a tradução dos atos tecnológicos em atos jurídicos.

Uma dificuldade é que o Código tem natureza altamente binária, em virtude da qual surge o determinismo tecnológico - que coloca a tecnologia, em muitas de suas expressões, em seara não-sindicável - e o Direito não consegue conciliar-se com a ideia de determinismo tecnológico porque não tem uma mundividência que justifique tal realidade.

Embora seja exagero falar em ciberlibertarianismo absoluto, forma-se um anseio social (Sociedade) de que a lei não atue na totalidade do Ciberespaço e este anseio se reflete na Tecnologia (que apreende esta inquietação dentro de sua própria autonomia). O Direito reage a essa comunicação social entrando na ofensiva, enquanto a Tecnologia reage à mesma comunicação social entrando na defensiva. 
Um aspecto peculiar do ciberlibertarianismo é que não reivindica a ausência do Código; apenas do regramento jurídico. O texto A cypherpunk's Manifesto, escrito por Eric Hughes, diz que os cypherpunks desprezam a regulação [jurídica] da criptografia; e o texto The Crypto-Anarchist Manifesto, de Timothy May, explica que a Tecnologia está deixando o ambiente acadêmico e começando e encontrar viabilidade econômica, após o que se tornará um poder invencível.

Cypherpunks deplore regulations on cryptography, for encryption is fundamentally a private act. The act of encryption, in fact, removes information from the public realm. Even laws against cryptography reach only so far as a nation's border and the arm of its violence. Cryptography will ineluctably spread over the whole globe, and with it the anonymous transactions systems that it makes possible (A Cypherpunk's Manifesto, 1993)

The technology for this revolution--and it surely will be both a social and economic revolution--has existed in theory for the past decade. The methods are based upon public-key encryption, zero-knowledge interactive proof systems, and various software protocols for interaction, authentication, and verification. The focus has until now been on academic conferences in Europe and the U.S., conferences monitored closely by the National Security Agency. But only recently have computer networks and personal computers attained sufficient speed to make the ideas practically realizable. And the next ten years will bring enough additional speed to make the ideas economically feasible and essentially unstoppable (The Crypto-Anarchist Manifesto, 1992)

O Código, então, se apresenta como um fenômeno global que independe da lei, senão completamente, até o limite de cada fronteira soberana ou dos domínios identificáveis da internet (como grande extensão da deepweb).

Nossa escolha não é entre 'regulação' e 'não regulação'. 0 código regula. Ele implementa valores, ou não. Permite liberdades, ou as desqualifica. Protege a privacidade ou promove o monitoramento. As pessoas escolhem como o código faz essas coisas. As pessoas escrevem o código. Assim, a escolha não é se as pessoas vão decidir como o ciberespaço é regulado. Pessoas - codificadores - irão. A única escolha é se nós, coletivamente, teremos um papel no que eles escolherão - e assim em determinar como estes valores serão regulados - ou se, coletivamente, permitiremos que os codificadores selecionem nossos valores por nós (LESSIG, 2000)

Teubner admite o cenário supra retratado ao discorrer sobre Lex Digitalis em paralelo à Lex Mercatoria em The horizontal effect of fundamental rights on "private parties" within Autonomous Internet Law (TEUBNER e KARAVAS, 2005: 24-27).

O resultado é que pela primeira vez o Direito se depara com o desafio de compreender um sistema cuja independência e autonomia evoluíram de tal modo, 
que para comunicar-se com ele é preciso reaprender a comunicação: desenvolver um vocabulário que o torne apto a compreendê-lo (common ground $)^{10}$.

Este regulador é código - o software e o hardware que fazem o ciberespaço como ele é. Este código, ou arquitetura, define os termos em que a vida no ciberespaço é experimentada. Determina o quão fácil é proteger a privacidade ou quão fácil é censurar a fala. Determina se 0 acesso à informação é geral ou se a informação é zonificada. Afeta quem vê o quê ou o que é monitorado. 0 código do ciberespaço regula de uma série de maneiras impossíveis de vislumbrar, a menos que se comece a compreender sua natureza (LESSIG, 2000).

O Direito alcança conclusões por meio de seu contato com as teorias sociais que lhes transferem os seus conhecimentos sem modifica-los no processo. A mesma lógica se aplicaria inversamente se o Direito precisasse transmitir conhecimentos à Tecnologia. Mas como isto será possível se os dois sistemas não conseguem se comunicar porque não possuem um common ground linguístico?

Apoiado pela validade exclusiva do "código binário" lícito/ilícito, o direito desenvolve uma estrutura complexa de conceitos que chamamos de "doutrina", que é, de fato, incomensurável com teorias científicas. 0 código jurídico, que é diferente de outros "códigos binários" da sociedade, constitui a base da autonomia inevitável da doutrina jurídica, a qual exclui categoricamente qualquer tomada de poder unilateral por parte das teorias sociais (TEUBNER, 2015:7)

A interdependência das racionalidades sociais faz com que seja necessária a interligação entre teoria social e doutrina, e a interligação só se dá com base na autonomia mútua, o que implica em processos independentes. Direito e Tecnologia, cada um terá sua gramática, estas construídas internamente nos sistemas sem interferência - apesar de "inspiradas" nas estruturas emprestadas via acoplamento.

A boa notícia é que se a regulação depende da ruptura dos circuitos comunicativos dos sistemas envolvidos, a primeira etapa já ocorreu, resta a construção da ponte entre os sistemas.

\section{Relação entre responsividade do Direito e comunicação}

O direito permite que análises externas de problemas postos pelas teorias sociais o desafiem, mas restringe esta dinâmica com critérios de seleção próprios;

\footnotetext{
${ }^{10}$ Conforme discutido no capítulo III.2 quando se explicou que parece ter ocorrido uma evolução desde o surgimento dos sistemas Direito, Política e Economia, ou seria uma característica peculiar da tecnologia; embora não se possa dizer que um sistema tenha mais autonomia ou do que o outro (porque todos são fechados, completos e independentes), a Tecnologia se traduz em fenômenos sociais de maneira mais direta e eficiente que os demais - com exceção do próprio Direito, colocando-o em uma posição não explorada em que a norma jurídica é desejável, mas não indispensável.
} 
a partir daí o direito os reconstrói [aos problemas], internamente em sua própria língua, para que possa conciliar problemas e soluções.

Somente quando esse processo de reconstrução coloca a argumentação jurídica em uma posição na qual ela possa distinguir dentro do direito entre normas e fatos, entre conceitos jurídicos e interesses sociais, é que se alcança um ponto no qual o direito é capaz de levantar a questão da adequação social, em outras palavras, a questão de saber se as decisões judiciais fazem justiça a esses aspectos do mundo exterior, tal como estes foram reconstruídos internamente (TEUBNER, 2015:7)

A interconexão, por sua vez, possibilita determinar, do interior do sistema Direito, se as formulações jurídicas respondem com sensibilidade às estruturas e aos problemas dos fenômenos sociais (como) percebidos pelo direito (responsividade).

as teorias sociais fornecem análises estruturais de fenômenos sociais, identificam problemas sociais que são gerados por esses fenômenos em seu ambiente e são capazes de fornecer informações diretivas com vistas a encontrar possíveis soluções para os problemas que submetem a uma comparação funcional. Isso é algo com o que a doutrina jurídica pode se conectar caso (diacronicamente, na dependência da trajetória dos conceitos jurídicos historicamente desenvolvidos, e, sincronicamente, no contexto do código legal e dos programas jurídicos existentes) ela desenvolva normas independentes (TEUBNER, 2015:7)

O último estágio deste processo é a percepção de como a norma jurídica será aceita no mundo social para aprimorá-la; o que se dá quando conflitos sociais semelhantes aos endereçados são trazidos outra vez ao Direito (monitoramento para a correção das soluções).

Esse ciclo é necessário para que o Direito compense as eventuais alienações resultantes da tradução dos conflitos sociais para a sua linguagem, o que pode culminar na produção de soluções que fazem sentido apenas internamente.

A responsividade do direito em relação às ciências sociais, portanto, não se limita à reconstrução de conflitos antes da decisão judicial, mas estende-se à observação das consequências dessas decisões conforme elas surgem no seio da sociedade (TEUBNER, 2015:7)

A existência de conflitos para Teubner não é um mal. Visões diferentes (mundivisões) entre o sistema Direito e os demais sistemas possibilitam o "malentendido produtivo" que é uma oportunidade para o Direito encarar as teorias sociais como desafios externos e perceber que não interessa isolá-las, mas reconstruí-las dentro de si para formular conceitos próprios que serão resolvidos via formação de normas (TEUBNER, 2015: 7).

A responsividade não é um portal por meio do qual o conhecimento social alcança o direito, mas antes um veículo para que se perceba como os sistemas são subjetivos e como todas as perspectivas são relativas de um para o outro. Dá-se, 
deste modo, a "tradução da teoria social na doutrina jurídica" (TEUBNER, 2015, 7).

O processo não ocorre como mera transferência de significado idêntico para outra linguagem, mas de tal forma que a própria terminologia do direito se permite ser desafiada, de acordo com as condições de sua lógica de desenvolvimento interior, por construções da teoria social e, em consequência, ser inspirada a criar novas formações estruturadas de modo bastante diferente (TEUBNER, 2015:7).

Quais as consequências do vácuo comunicativo entre Tecnologia e Direito? O sistema Jurídico não consegue processar uma versão dos problemas postos pelas teorias sociais que digam respeito à Tecnologia e não consegue produzir soluções jurídicas efetivas e coerentes para estes problemas (nãoresponsividade).

Com a promoção a sistema de segundo grau, como ocorreu com a Tecnologia, o processo se torna mais violento porque instaura a comunicação entre os sistemas (ground zero), o que é diferente da manutenção de uma comunicação estabelecida - realidade com a qual os juristas estão habituados.

Considerados os três estágios acima narrados - (i) análise externa, (ii) formulação jurídica e (iii) percepção da adequação da solução jurídica - o analfabetismo tecnológico no Direito cria um efeito em cadeia no qual a análise externa é falha, logo a solução jurídica formulada é ineficaz e o "controle de qualidade" se torna impossível.

\section{Comunicação é requisito de regulação: pré-regulação}

O Direito precisa absorver a Tecnologia internamente, em sua própria linguagem, para conciliar divergências, enfrentar problemas e oferecer soluções tendo em vista os sistemas sociais e suas estruturas fundamentais - que informam o Direito e são normatizadas por ele em retorno.

A sociedade já incorporou a Tecnologia em sua arquitetura, isto é irrefutável, tanto que, de outro modo, esta não teria se constituído em subsistema principal; o que ilustra bem porque a responsividade não é uma porta de acesso ao meio jurídico, mas antes um meio de ressaltar as diferenças entre realidade e expectativas.

Para que este contraponto se torne um "mal-entendido produtivo", é preciso que o desafio externo da Tecnologia seja enfrentado pelo Direito, que o conceito de tecnologia e suas variáveis, principalmente o Código, sejam traduzidos em linguagem jurídica, reformulados e revertidos em normas jurídicas eficazes.

A dificuldade maior, conforme apontando no tópico anterior, é que a instauração de nova comunicação se revelou mais desafiadora do que a 
manutenção do diálogo já existente, demandando uma autorregulação mais drástica no Direito.

Heterorregulação inversa (do Direito pela Tecnologia) não implica obrigatoriamente na criação de normas de tecnologia a partir da releitura do sistema jurídico no ambiente interno tecnológico (mas pode ter este resultado se o Código se alterar em função desta relação).

A proposta ora defendida é a abertura de um canal sui generis de interferência da Tecnologia na gramática jurídica e de transformação dos pressupostos do Código (reflexão sobre a arquitetura de algoritmos segundo a lógica tecnológico-jurídica).

"Gramática" não se limita à intervenção no vocabulário, mas reflete a inserção de sentido tecnológico, compreensão a respeito do sistema Tecnologia e à sua dificuldade de permeabilidade - determinismo tecnológico.

Assim, a interferência encerraria um processo simbiótico no qual as normas jurídicas poderiam impactar na elaboração e na reelaboração do Código (único caminho para alterar os pressupostos da binariedade, que é inescapável):

In order to develop legal standards for the 'code' one needs to analyse the specific risks of the cyberspace architecture. What specific dangers does the 'code' entail for individual autonomy? How does the code impact on the autonomy of social institutions? And the legal control standards need to be reconstructed specifically for the architecture of the internet. What kind of legal meta-rules have to be developed in order to secure individual and institutional autonomy against the 'code' (TEUBNER, 2004)

Normalmente a regulação ocorre a partir da observação autônoma da realidade de um sistema refletida no outro, em um regime no qual ambos traduzem a realidade social de maneira muito semelhante.

Sem embargo, se tem observado no texto que, falando de DireitoTecnologia, um sistema não entende a percepção do outro sobre a realidade social porque não há um histórico de onde tentar extrair a lógica alheia (comunicação); a previsão de como a norma jurídica/tecnológica será aceita no mundo social é falha, e não há conflitos sociais semelhantes para serem monitorados como mecanismo de correção das soluções.

Tudo é muito recente.

Traditional law is based on an institutional, procedural and personal separation of law-making, law application and law enforcement. This is also true to a certain degree for law making in the private sector. The strange effect of digitalization is a kind of nuclear fusion of these three elements which means the loss of an important constitutional separation of power.

A second issue is the trias of regulation of conduct, construction of expectations, and resolution of conflict. Traditional law cannot be reduced to one of these aspects but realizes them all, however within separate institutions, normative cultures and principles of legality. There is a (hidden) constitutional dimension in this separation. Again, the digital embodiment of normativity in the 'code' 
reduces these different aspects just to one, to the aspect of electronic regulation of conduct.

The third issue is calculability of normativity. In traditional law, formalisation was rather limited. The (in)famous effects of legal formalism have been relatively harmless as compared with the effects of the 'code' which allows for a hitherto unknown formalisation of rules. The strict binary relation $0-1$ which in the real world was limited to the legal code in the strict sense of legal/illegal, is now extended in the virtual world to the legal programs, to the whole ensemble of substantive and procedural structures that condition the application of the binary code. This excludes any space for interpretation. Normative expectations which traditionally could be manipulated, adapted, changed, are now transformed into rigid cognitive expectations of inclusion/exclusion of communication (TEUBNER, 2004)

É o que se nomeia neste texto "pré-regulação": a necessidade de um condicionamento para permitir a regulação (em sentido estrito) futura; a primeira providência mútua sendo observar e traduzir internamente o vocabulário alheio.

Posteriormente este vocabulário seria convertido em ferramenta de apreensão da realidade (mundividência) do outro para a criação de uma versão própria daquela realidade.

A tarefa é particularmente árdua para o Direito. Enquanto os demais sistemas sociais são habituados a absorvê-lo, internalizar versões do vocabulário jurídico e sofrer intervenção regulatória, mas ao sistema jurídico, quando muito, lhe bastavam as visões (econômica ou política) processadas internamente ou extrair um sentido dos demais sistemas que viesse pronto, "mastigado" pela sociedade.

O sentido "mastigado" pela sociedade sobre a Tecnologia, inobstante, não é inteligível ao Direito porque o sistema social se transformou em sociedade de dados em um ritmo muito rápido e natural, de modo que sua comunicação a este respeito não é didática - seria um ruído ensurdecedor para o sistema Jurídico.

O Direito precisa, pois, ir até o sistema Tecnologia entendê-lo para, a partir daí, compreender (uma versão) sua e ainda a outra, social.

\section{Constituição Digital}

A resposta de Teubner para este dilema seria a formulação de uma Constituição Digital. Com ela, seria possível o acoplamento estrutural entre Direito e Tecnologia com a absorção pelo primeira da gramática tecnológica.

O autor analisa, em Societal Constitutionalism: alternatives to Statecentred Constitutional Theory, a possibilidade de uma Constituição sem Estado e destaca que as batalhas travadas na internet em nome de uma ciberanarquia e a comercialização da regulamentação governamental de conflitos políticos são um indicativo do caos que está se instalando e que conduz gradualmente à organização de uma Constituição Digital. 
As normas legais não são produzidas só na regulamentação de conflitos por cortes oficiais internacionais e nacionais, mas em sede de órgãos de resolução de disputas sociais não-políticas, organizações internacionais, tribunais de arbitragem, órgãos mediadores, comitês de ética e sistemas de tratados (TEUBNER, 2004: 13).

Este panorama indicaria que as fontes dominantes do Direito migraram para a periferia da lei, nas fronteiras com outros setores da sociedade. Portanto, os centros existentes de elaborações de lei (parlamentos nacionais, instituições legislativas e acordos intergovernamentais) não seriam mais a origem de todas as normas constitucionais.

Teubner emende que o Direito não está excluído do fenômeno legal/constitucional porque tais processos ocorrem simultaneamente - como visto anteriormente - nos sistemas Social e Jurídico.

A constitution is always bridging two real ongoing processes: from the viewpoint of law it is the production of legal norms, which is interwoven with fundamental structures of the social systems; from the viewpoint of the constituted social system it is the production of fundamental structures of the social system which at the same time inform the law and are in turn normed by the law (TEUBNER, 2004:16).

A resposta aos problemas do Cyberspace, por conseguinte, deveria vir de uma Constituição própria da internet que proporcionasse o acoplamento estrutural funcional entre estruturas digitais fundamentais e formas legais.

National regulation tends to fail due to implementation problems raised by the transnational nature of digital communication. In contrast, an internet regulation, desired by all good men today, through legitimate international lawmaking in turn threatens, alas, to fail due to the difficulties in reaching intergovernmental consensus (TEUBNER, 2004:17)

The internet's self-made law profits not just from the problems with the other two forms of regulation, but additionally from the technical advantages the code's architecture offers for highly efficient regulation. Thanks to electronic means of constraint, it can largely do without regulation controlled by sociolegal expectations, but the electronic means are in turn controlled by meta-legal norms (TEUBNER, 2004:17)

A Constituição poderia ser elaborada unilateralmente por um governo, via acordo internacional, por instituições como o Internet Corporation for Assigned Names and Numbers (ICANN) ou o World Wide Web Consortium ou pela Internet Engineering Task Force (TEUBNER, 2004:18). Fato é que, segundo Teubner, a Constituição Digital é necessária para que se forme um vínculo estrutural efetivo entre Direito e tecnologia (comunicações digitais).

A Constituição Digital idealizada por Teubner deveria regular duas grandes áreas políticas: a lei do Estado e os direitos fundamentais dos cidadãos; o que seria um desafio por causa da dualidade da autonomia social nos subsistemas e das dinâmicas de controle nos setores espontâneos e organizados da sociedade. 
Em relação ao Ciberespaço, o autor destaca que Lessig antecipou o temor quanto a uma Internet controlada por coalizões de interesses econômicos e políticos (TEUBNER, 2004: 23).

Sobre o receio de Lessig, Teubner destaca que a internet teve um começo anárquico quando construída sobre os princípios da inclusão de todos, do anonimato, da liberdade e da heterarquia; todavia, a tendência atual seria politicamente e economicamente motivada em direção às intranets, redes fechadas baseadas em exclusão, controle, hierarquia e agendas objetivas.

A solução para este dilema seria, finaliza o texto, uma Constituição da Internet que distinguisse o setor público espontâneo dos setores formais altamente organizados e cuja principal função fosse mantê-los sob rédea firme, controlando a ambos (TEUBNER, 2004: 23).

\section{Aplicação prática da solução proposta}

É preciso inserir tecnologia no universo dos juristas e aplicadores do Direito ${ }^{11}$.

Seria interessante que conceitos de tecnologia - sob a forma de direito digital - fossem incluídos nas grades curriculares das universidades e faculdades; nos cursos de formação dos profissionais de Direito (Magistratura, Ministério Público, etc.); na prova para admissão nos quadros da Ordem dos Advogados; e que cursos de extensão fossem ministrados nos órgãos do Poder Judiciário, Ministério Público, Polícia e demais carreiras, tanto para bacharéis em direito quanto para graduados de outras formações, mas com atuação jurídica ou jurídicoadministrativa.

Outra medida seria replicar a providência adotada no artigo $5^{\circ}$ do Marco Civil da Internet e no artigo $5^{\circ}$ do projeto de lei sobre dados pessoais (PL 5276/2016), em que constam dos textos legais glossários relativos às expressões técnicas mais importantes.

Evidente que a aclimatação do Direito à Tecnologia - e vice-versa - levará tempo. As sugestões acima pretendem somente acelerar e metodificar o processo enquanto a Constituição Digital não vira realidade - se é que a ideia prosperará.

A diferença entre a necessidade de compreender e absorver a gramática tecnológica, em comparação a outros campos do saber, como o ambiental, o minerário, o bancário; é que a tecnologia, ao contrário destes, é pulverizada na sociedade e nos respectivos "ramos" do direito. É possível falar em implicações tecnológicas nas searas ambiental, trabalhista, minerária etc., basta imaginar as

\footnotetext{
${ }^{11}$ Vários exemplos práticos são descritos por Vladimir Passos de Freitas em artigo A tecnologia vai impactar o direito e seus profissionais, publicado no Consultor jurídico em 06.08.2017 e disponível em <https://www.conjur.com.br/2017-ago-06/segunda-leitura-tecnologia-impactardireito-profissionais $\rangle$. Acesso em 04.12.2017. 
consequências da automação, do uso de robôs, da engenharia genética, do home office, e assim por diante.

Ademais, o Direito é institucionalmente orgulhoso. Admitir conceitos como o de determinismo tecnológico é um tremendo desafio aos seus operadores porque coloca o Direito em posição de impotência.

A vantagem do conhecimento tecnológico, sob outro olhar, é ter recursos dentro do próprio determinismo para alcançar as soluções pretendidas. No caso do WhatsApp, para ilustrar, a impossibilidade de acesso ao conteúdo das mensagens em plaintext poderia ser compensada com a apreensão de metadados, dados geolocalizacionais, fotos, vídeos, áudios.

A informação tem valor. Saber que a maioria dos e-mails não utiliza criptografia de armazenamento, apenas de tráfego, ficando armazenada nos data centers das operadoras em plaintext, por exemplo, seria útil para o pedido de apreensão de correio eletrônico como uma providência viável, ao contrário (outra vez) das conversas de WhatsApp que ficam armazenadas encriptadas no provedor.

A compreensão a respeito do funcionamento das plataformas de dois lados, para dar outro exemplo, faz enorme falta aos operadores do Direito. Para demonstrar, pergunta-se: seria o Uber uma empresa contratante de motoristas ou uma plataforma de dois lados? Em que a subordinação imposta aos usuáriospassageiros é menos relevante do que a imposta aos usuários-motoristas?

O Direito não consegue se decidir entre classificar a relação entre o Uber e seus motoristas como de trabalho ou não. Há exemplos em ambos os sentidos. Seria a razão para esta insegurança o analfabetismo tecnológico (ausência de mecanismos linguísticos e de comunicação)? (G1, 2016; CONJUR, 2017; TELLES, 2017; FÁBIO, 2017).

Quando se trata de regras políticas ou códigos de conduta particulares, é possível que o Direito exija dos agentes tecnológicos ações que são contrárias às convicções daqueles (e à realidade tecnológica); mas quando o assunto é a arquitetura do Código, o conhecimento do jurista sobre tecnologia é fundamental na busca de soluções alternativas porque o dissenso teórico ou moral se torna inócuo em face da binariedade.

Se o Direito aprender a manipular a realidade tecnológica para dentro da realidade jurídica, poderá tentar moldar o Código no instante de desenhá-lo ou redesenhado, para buscar atender aos seus anseios (legais-dogmáticos e pricipiologicamente-morais) projetados. Juridicidade e determinismo não precisam ser inconciliáveis.

\section{Conclusão}

A leitura da obra de Teubner é um exercício muito rico de imersão sociológico-jurídica cujas implicações práticas são difíceis de se apreender em 
uma análise mais perfunctória porque remetem a uma reflexão teórica densa e intricada.

De fato, tentar aplicar as ideias de Gunther Teubner a todo e qualquer problema jurídico seria um desafio para poucos, sendo tamanha a audácia de tal empreitada que a maioria não ousaria nem sequer tentar.

Em relação ao tema de pesquisa proposto, não obstante, qual seja: a compreensão do porquê o Direito impor tanta resistência à Tecnologia e como solucionar este impasse, os pensamentos de Teubner sobre a natureza hermeticamente fechada do sistema jurídico caem como uma luva.

Embora cognitivamente abertos, os subsistemas têm compleição de absoluta clausura, opondo resistência natural uns aos outros.

Para apreender, e eventualmente mitigar esta clausura, é preciso assimilar como os sistemas respondem a seus meios envolventes e aos demais sistemas, e de que maneira podem, supostamente, interagir direta, indiretamente ou de ambas as formas.

Como viabilizar a regulação como heterorregulação em uma sistemática de ausência comunicativa? Para tanto, seria preciso entender que a autorregulação é uma maneira de evolução intrassistêmica a partir de versões das realidades alheias que são capturadas por cada sistema, normalmente via acoplamento estrutural.

A evolução, então, explica de que maneira a Tecnologia se elevou à categoria de sistema de segundo grau e de que modo sua interação com o sistema Direito é particularmente diversa daquilo que se observa em relação aos demais subsistemas.

A resiliência do Direito se deve, sobretudo, ao fato de que não pode haver manutenção daquilo que não existe e a comunicação entre Direito e Tecnologia é inexistente. Os sistemas carecem de uma gramática ou vocabulário para que possam processar aquilo que percebem no exterior e traduzir em realidade interna: estrutura linguística.

De fato, a carência de uma estrutura linguística (apta a absorver a tecnologia) é ainda mais expressiva por parte do sistema Direito que, até por questões culturais e históricas, é acostumado a ter trânsito nos demais sistemas, mas nunca a dar-lhes o mesmo acesso em sua privacidade.

Incentivado a superar sua rigidez quanto à Tecnologia, o Direito pode construir uma gramática tecnológica que o torne mais literato e pronto a absorver versões das expectativas socais voltadas para aquele campo.

Seria possível, nesta linha, conciliar legalidade e determinismo tecnológico, aprender a lidar com a binariedade do Código e perceber como influenciá-lo. 
Para tornar factível o acoplamento estrutural entre os sistemas analisados, Teubner sugere que a linguagem tecnológica seja transformada em uma Constituição Digital diferente do Código (programação), escrita.

Esta Constituição seria o manual de alfabetização do Direito e, em contrapartida, poderia ser classificada como prova de eficiência do acoplamento estrutural porque, necessariamente, seria uma construção normativa no sistema Tecnologia a partir de uma mundividência jurídica refletida em uma esfera extrajurídica.

\section{Referências Bibliográficas}

APUZZO, M. WhatsApp encryption said to stymie wiretap order. The New York Times. Disponível em <http://www.nytimes.com/2016/03/13/us/politics/what sapp-encryptionsaid-to-stymie-wiretap-order.html?_r=0>. Acesso em 15.03.2016.

APPLE. Apple inc.'s reply to government's opposition to Apple Inc.'s motion to vacate order compelling Apple Inc. to assist agents in search. Data: 22.03.2016. Disponível em: <https://cryptome.org/2016/03/usg-apple177.pdf>. Acesso em 24.01.2018.

BARBOSA, R. Tércio Sampaio: "Juízes operam conceitos velhos em um mundo novo". Gazeta do povo. Disponível em: <http://www.gazetadopovo.com.br/justica/tercio-sampaio-juizes-operamconceitos-velhos-em-um-mundo-novo-4fniz3cac3p5jpu70hzu40qnw. 01.06.2017>. Acesso em 22.06.2017.

CHACON, E. M. Considerações sobre cooperação internacional a partir do novo CPC. Migalhas, 2105. Informativo $\mathrm{n}^{\circ}$ 3.605. ISSN 1983-392X. Disponível em <http://www.migalhas.com.br/dePeso/16,MI219609 ,11049-Consideracoes+sobre+cooperacao+internacional+a+partir+do+no vo+CPC> Acesso em 23.08.2017.

CHACON, E. M. Encriptação e acesso judicial. Migalhas, 2016. Informativo ${ }^{\circ}$ 3.826. ISSN 1983-392X. Disponível em <http://www.migalhas.com.br/d ePeso/16,MI236262,81042-encriptacao+e+acesso+judicial>. Acesso em 22.03.2016.

CHACON, E. M. A criptografia é uma realidade. LinkedIn, 2017. Disponível em <https://www.linkedin.com/pulse/encripta\%C3\%A7\%C3\%A3o-eacesso-judicial-eduarda-chacon?published=t $>$. Acesso em 07.02.2016. 
CONJUR. Falta de eventualidade e de salário impedem relação de emprego com a Uber. Revista Consultor Jurídico. Disponível em $<$ https://www.conjur.com.br/2017-jul-23/independencia-motoristaimpede-relacao-emprego-uber>. Acesso em 06.02.2018.

GREEMBERG, A. WhatsApp just switched on end-to-end encryption for hundreds of millions of users. Wired Magazine, 2014. Disponível em <http://www.wired.com/2014/11/whatsapp-encrypted-messaging/>. Acesso em 08 março 2016.

ESTADÃO. WhatsApp chega a 120 milhões de usuários no Brasil. Redação. Disponível em <http://link.estadao.com.br/noticias/empresas, whatsappchega-a-120-milhoes-de-usuarios-no-brasil,70001817647>; Acesso em 06.02.2018.

FÁBIO, A. C. Motorista de Uber é funcionário? O que a Justiça brasileira tem decidido. Nexo Jornal. Disponível em <https://www.nexojornal.com.br/expresso/2017/06/08/Motorista-de-Uber -\%C3\%A9-funcion\%C3\%A1rio-O-que-a-Justi\%C3\%A7a-brasileira-temdecidido>. Acesso em 06.02.2018.

FRAZÃO, A. A atual realidade brasileira e a crescente tensão entre os imperativos econômicos e o Estado Democrático de Direito. Democracia e Direito. Disponível em <http://anafrazao.com.br/files/publicacoes/2017-05-17-democracia_e_me rcados_A_crescente_tensao_entre_os_imperativos_economicos_e_o_Est ado_Democrati co_de_Direito.pdf >. Acesso em 22.06.2017.

FREITAS, V. P. A tecnologia vai impactar o direito e seus profissionais. Consultor jurídico. Disponível em <https://www.conjur.com.br/201 7ago-06/segunda-leitura-tecnologia-impactar-direito-profissionais>. Acesso em 04.12.2017.

G1. Justiça do Reino Unido decide que motoristas são empregados do Uber. G1 - Portal de Notícias da Globo. Tecnologia e Games. Disponível em $<$ http://g1.globo.com/tecnologia/noticia/2016/10/justica-do-reino-unidodecide-que-motoristas-sao-empregados-do-uber.html>. Acesso em 06.02.2018.

HUGHES, E. A Cypherpunk's Manifesto. 1993. Disponível em <https://www.activism.net/cypherpunk/manifesto.html>. Acesso em 04.12.2017. 
ICO. Encryption. Informations Commissioner's Office - ICO. Disponível em $<$ https://ico.org.uk/media/for-organisations/guide-to-dataprotection/encryption-1-1.pdf>. 04.04.2017. Acesso em: 22.06.2017.

ICO. Protecting personal data in online services: learning from the mistakes of others. Informations Commissioner's Office - ICO. Disponível em $<$ https://ico.org.uk/media/for-organisations/documents/1042221/protectin g-personal-data-in-online-services-learning-from-the-mistakes-of-others .pdf>. Acesso em 22.06.2017.

LESSIG, L. Code is Law. On liberty in cyberspace. Harvard Magazine, 2000. Disponível em <http://harvardmagazine.com/2000/01/code-is-law-html>. Acesso em 22.06.2017.

LESSIG, L. Code version 2.0. Disponível em: <http://codev2.cc/.> Edição eletrônica. New York: Basic Books, 2006. Acesso em 22.06.2017.

MAY. T. The Crypto Anarchist Manifesto. 1992. Disponível em <https://www.activism.net/cypherpunk/crypto-anarchy.html>. Acesso em 04.12.2017.

NEVES, R. F. Acoplamento estrutural, fechamento operacional e processos sobrecomunicativos na teoria dos sistemas sociais de Niklas Luhmann. Dissertação para obtenção de título de mestre em Sociologia. Universidade de São Paulo, 2005.

ROSNAY, M. D. Peer-To-Peer Law: Distribution as a Design Principle for Law. Media@LSE, London School of Economics and Political Science ("LSE"). Disponível em <http://www.lse.ac.uk/media-andcommunications/research/working-paper-series>. Londres, 2014. Acesso em 22.06.2017.

SELBST, D.; TICONA, J. Supreme Court must understand: cell phones aren't optional. Wired Magazine, 2017. Disponível em <https://www.wired.com/story/supreme-court-must-understand-cellphones-arent-optional/>. Acesso em 30.11.2017.

SREEHARSHA, V.; ISAAC, M. Brazil arrests Facebook Executive in WhatsApp data acess case. The New York Times, 2016. Disponível em <http://www.nytimes.com/2016/03/02/technology/brazil-arrests-facebook -executive-in-data-access-case.html?_r=0>. Acesso em 09 março 2016.

STECKLOW, S. Facebook exec arrested and released in Brazil over encrypted WhatsApp messages. New York Magazine. Disponível em <http://nymag.com/following/2016/03/facebook-exec-arrested-in-brazilover-whatsapp.html\#>. Acesso em 09.03.2016. 
TELLES, F. L. Q. Relação entre motoristas e Uber é de trabalho. Gazeta do povo. Disponível em <http://www.gazetadopovo.com.br/opinia o/artigos/relacao-entre-motoristas-e-uber-e-de-trabalho-caveox9qelggtuc 28vz1jammn>. Acesso em 06.02.2018.

TEUBNER, G. Dilemmas of Law in the Welfare State. Belin/New York: Walter de Gruyter, 1986.

TEUBNER, G. O Direito como sistema autopoiético. Trad. José Engrácia Nunes. Lisboa: Ed. Calouste Gulbekian, 1993.

TEUBNER, G. Societal Constitutionalism: Alternatives to State-Centered Constitutional Theory? Constitutionalism and Transnational Governance, Christian Joerges, Inge-Johanne Sand and Gunther Teubner, eds., Oxford Press, pp. 3-28, 2004. Disponível em <https://ssrn.com/abstract=876941 >. Acesso em 04.12.2017.

TEUBNER, G. Rights of non-humans? Electronic agents and animals as new actors in politics and law. Journal of Law and Society, Vol. 33, pp. 497521, 2006. Disponível em <https://papers.ssrn.com/sol3/papers.cfm?a bstract_id=892962>. Acesso em 04.12.2017.

TEUBnER, G. The Anonymous Matrix: Human Rights Violations by 'Private' Transnational Actors. Modern Law Review, Vol. 69, pp. 327346. Blackwell Publishing. Maine: 2006. Disponível em <https://ssrn.com/abstract=893106>. Acesso em 04.12.2017.

TEUBNER, G. Law and social theory: three problems (Direito e teoria social: três problemas). Tempo Social, 2015 Disponível em <http://dx.doi.org/10.1590/0103-2070201524>. Acesso em 04.12.2017.

TEUBNER, G.; KARAVAS, V. The Horizontal Effect of Fundamental Rights on 'Private Parties' within Autonomous Internet Law. Constellations: An International Journal of Critical and Democratic Theory, 2005. Disponível em <http://onlinelibrary.wiley.com/doi/10.1111/j.13510487.2005.00415.x/abstract>. Acesso em 04.12.2017.

TRUBEK, D.; COUTINHO, D. R.; SCHAPIRO, M. G. New State Activism in Brazil and the Challenge for Law. Paper presented at the Harvard Law School Institute for Global Law and Policy June 2012. Disponível em <http://iglp.law.harvard.edu/wp-content/uploads/NSAHarvardDraft_Trub ek_etal.pdf $>$. Acesso 29.08.2017.

YADRON, D. Facebook, Google e WhatsApp plan to increase encryption of user data. Disponível em <http://www.theguardian.com/technology/2016 
/mar/14/facebook-google-whatsapp-plan-increaseencryption-fbi-apple>. Acesso em 15.03. 2016.

\section{Normas e julgados}

BRASIL. Lei $\mathbf{n}^{\circ} 12.965$ de 23 de abril de 2014. Marco Civil da Internet.

Estabelece princípios, garantias, direitos e deveres para o uso da Internet no Brasil. Diário Oficial da União, Seção 1, 24/4/2014, Página 1 (Publicação Original). Disponível em <http://www.planalto.gov.br/ ccivil_03/_ato2011-2014/2014/lei/112965.htm>. Acesso em 22.06.2017.

BRASIL. Decreto n⿳ 8.777, de 11 de naio de 2016. Institui a Política de Dados Abertos do Poder Executivo Federal. Diário Oficial da União de 15.05.2016. Disponível em <http://www.planalto.gov.br/ccivil_03 /_ato2015-2018/2016/decreto/D8777.htm>. Acesso em 22.06.2017.

BRASIL. Decreto $\mathbf{n}^{\circ} 8.771$ de 11 de maio de 2016. Decreto regulamentador do Marco Civil da Internet. Diário Oficial da União de 11.05.2016. Disponível em <http://www.planalto.gov.br/ccivil_03/_Ato20152018/2016/Decreto/D8771.htm>. Acesso em 22.06.2017.

BRASIL. PL 5276/2016. Autoria Poder Executivo. Câmara Federal. Disponível em <http://www.camara.gov.br/proposicoesWeb/fichadetramitacao?id Proposicao=2084378> . Apresentação 13.05.2016. Acesso em 22.06.2017

BRASIL. STF, ADI 5527. Relatora Min. Rosa Weber, audiência pública realizada nos dias 02 e 05 de junho de 2017. Pendente de julgamento.

BRASIL. STF, ADPF 403. Relator Min. Edson Fachin, audiência pública realizada nos dias 02 e 05 de junho de 2017. Pendente de julgamento.

BRASIL. STJ, RESP 1.568.935. Relator Min. Ricardo Villas Bôas Cueva. $3^{\mathbf{a}}$ Turma Cível. Data de julgamento: 05.04.2016. Data de publicação: DJe. 13.04.2016.

BRASIL. TJSP, Processo 1003266-82.2016.8.26.0271. Juíza Maria Helena Steffen Toniolo Bueno. Sentença homologando acordo em 03.02.2017. Trânsito em julgado certificado em 03.07.2017 